\title{
LA ESCUELA Y LA GUERRA DEL PACÍFICO. PROPUESTA DIDÁCTICA DE HISTORIA PARA LA INCLUSIÓN EDUCATIVA EN CONTEXTOS TRANSFRONTERIZOS DEL NORTE DE CHILE*
}

\section{School and the War of the Pacific; Didactic proposal for teaching history for educational inclusion in cross-border contexts in the north of Chile}

Carlos Mondaca Rojas ${ }^{\star *}$

Patricio Rivera Olguín ${ }^{* * *}$

Claudio Aguirre Munizaga ${ }^{* * * *}$

Recibido: 30 de octubre de 2012. Aprobado: 6 de marzo de 2013.

\section{RESUMEN}

En el presente trabajo se analizan los significados de la enseñanza de la Guerra del Pacífico en el norte de Chile, los cuales se relacionarían con ritos cívico-militares y una elaboración mítica del conflicto de 1879. Lo que se manifiesta en un nacionalismo exacerbado en profesores y estudiantes chilenos, el que es fomentado por el currículum, planes, programas y textos oficiales de estudios nacionales. Esta situación no permite el desarrollo de competencias inclusivas en las aulas. En este sentido, se propone desde la didáctica de la historia una enseñanza de la guerra para la inclusión educativa en contextos transfronterizos, basado en un análisis crítico de la información oficial disponible de la enseñanza del conflicto.

PALABRAS CLAVE: Guerra del Pacífico, didáctica de la historia, norte de Chile

* Proyecto Fondecyt № 1130859. Se agradece el apoyo del Proyecto de Investigación Científica y Tecnológica UTA No 5712-13. Asimismo, del Convenio de Desempeño Universidad de Tarapacá-Mineduc.

** Universidad de Tarapacá, Departamento de Educación, Arica Chile. Correo electrónico: cemondacar@uta.cl

*** Universidad Arturo Prat, Facultad de Ciencias Humanas, Iquique, Chile. Correo electrónico: patririv@unap.cl

**** Universidad de Tarapacá, Departamento de Educación, Iquique, Chile. Correo electrónico: crmunizaga@uta.cl 


\begin{abstract}
The present work analyzes the methods of teaching the War of the Pacific in the North of Chile, which relate to civic-military rituals and to the creation of myths about this 1879 conflict. This manifests itself as an exacerbated nationalism on the part of teachers and students, which is also promoted by the curriculum, its planning, programs, and the official nationwide school textbooks. This situation does not allow for the development of inclusive practices within the classrooms. In this respect, it is proposed, from a didactic perspective of the history, that the method of teaching the war should be carried out to enhance educational inclusion in cross-border contexts, based on a critical analysis of the official information that is available, on the teaching of the conflict.
\end{abstract}

KEYWORDS: Pacific War, teaching of history, northern Chile

\title{
I. INTRODUCCIÓN
}

La práctica docente sobre la guerra de 1879 en los colegios chilenos y sobre todo en las regiones fronterizas del norte de Chile -aun en pleno siglo XXI-, es excluyente y hegemónica. Esta fomenta la exaltación del concepto de patria transferido a los estudiantes como una expresión del nacionalismo estatal, sosteniendo a la asignatura de historia como generadora de la nacionalidad, tal cual lo planteará Foucault (1996), como una manifestación microfísica del poder. En este sentido, se produce un dispositivo de saber/ poder nacionalista que establece los contenidos de la guerra de $1879 \mathrm{y}$ un profesor de historia como transmisor de dichos conocimientos, para que los estudiantes se sientan chilenos y reafirmen su identidad nacional, a través no solo del conocimiento del conflicto, sino también en una adscripción casi mítica con las figuras de los héroes patrios y de las batallas; lo que excluye a un número importante de estudiantes de contextos transfronterizos provenientes de Perú y Bolivia, y otros que ya son chilenos, pero que contienen en su familia una memoria histórica inherente a sus propios héroes y batallas. ${ }^{1}$

Para el caso del norte de Chile, la exaltación de héroes -como por ejemplo, el caso del capitán Arturo Prat, que incluso es el símbolo máximo del héroe guerrero en Chile-, representa la exacerbación del ícono ejemplar e inmortal en la historia y la literatura. Situación que responde a esta intención de imaginarios iconoclastas heroicos que

1 Desde el cambio curricular de 1997 hasta el actual ajuste curricular de 2009, el primer ciclo de educación básica tiene, en el sector de Estudio y Comprensión del Medio Social y en el actual Historia, Geografía y Ciencias Sociales, la unidad de Identidad Nacional. 
se plasman en la educación e historia nacional desde la época decimonónica que reproduce desde entonces una identidad de perpetuación nacionalista en el tiempo, ${ }^{2}$ a pesar de existir tratados de paz entre Chile, Perú y Bolivia, ${ }^{3}$ existen aún tensiones incubadas desde la Guerra del Pacífico que son reflejo del culto nacionalista, que utiliza a la memoria histórica como elemento de exaltación patriótica y exclusión del otro, generando con ello una diferenciación con el otro del pasado que se actualiza, dadas las problemáticas diplomáticas del presente.

Cada cierto tiempo se recurre a estas mismas prácticas simbólicas xenofóbicas, que exacerban preferentemente desde el ámbito político, problemáticas fronterizas que en el contexto de la globalización e integración de los mercados son cada vez más difusas, producto de la constante y creciente migración transfronteriza en el norte de Chile, generando con ello un interesante escenario de conflictividad histórica con la alta inmigración presente en la zona.

En este contexto, resulta pertinente desarrollar propuestas para los procesos de enseñanza-aprendizaje en las aulas del presente siglo, pues hoy conviven en ellas, tres memorias históricas (peruana, boliviana y chilena), que son heredadas desde el Estado, como relatos nacionalistas en las aulas, lo que implica un desafío importante para los docentes de historia, que deben generar competencias pertinentes de integración en contenidos históricos y pedagógicos que permitan un vuelco importante en cómo tratar la guerra de 1879 en las escuelas desde una pedagogía inclusiva.

2 En la provincia de Iquique, por ejemplo: la primera plaza de la ciudad de Alto Hospicio, llamada del Encuentro de Naciones, el primer busto o escultura inaugurado en 1998 fue un busto del capitán Arturo Prat Chacón, precisamente en una plaza pública de la integración de los pueblos: ahora la imagen ritualística de carácter cívicomilitar engloba con su sacrificio patriota la causa del Estado nacional con una guerra desatada y el triunfo sobre el enemigo.

3 Entre Chile y Perú, existen los Tratados de Ancón en 1883, que pone fin a la Guerra del Pacífico, y Lima en 1929, que soluciona la problemática abierta por el Tratado de Ancón, en tanto a las provincias de Tacna y Arica, anteriormente a la guerra de 1879, eran peruanas, pero quedaron bajo ocupación chilena, hasta 1931, luego en virtud del Tratado de Lima, Tacna es entregada al Perú y Arica pasa a ser territorio chileno. En cuanto a Bolivia, en 1904, se sanciona al Tratado de Paz en que Bolivia cede la región de Antofagasta a Chile, por lo que pierde su acceso al mar; actualmente hay entre los tres países, tensiones por los territorios de la guerra de 1879, que están siendo judicializados por el Tribunal Internacional de La Haya. 


\section{EL DESAFÍO DE ENSEÑAR LA GUERRA DEL PACÍFICO EN LA FRONTERA NORTE DE CHILE}

Las propuestas educativas oficiales de enseñanza de la Guerra del Pacífico se caracterizan por tener un fundamento fuertemente nacionalista, desde un prisma de construcción en torno al otro, pero que exalta e incluye al nosotros, como vínculo de entidad nacional y que minimiza, y excluye a la vez al otro, que es visto como vencido. Esta situación manifiesta una violencia estructural (Galtung 1985), como en la mayoría de las zonas de frontera donde hay conflictos político-sociales, a los que no son indiferentes las regiones de Antofagasta, Tarapacá y Arica y Parinacota. ${ }^{4}$ Estas dinámicas fronterizas son producidas por las representaciones e imaginarios de los diferentes procesos de la guerra, imbricados a fechas específicas (23 de marzo, 21 de mayo y 7 de junio, entre otras), donde los triunfos y fracasos son percibidos siempre como victorias, claro reflejo de una transferencia cultural desde las esferas sociopolíticas de reproducción del Estado (Bourdieu 2003).

Asimismo, la fuerte migración y la permanente presencia de población peruana y boliviana en las regiones del norte chileno, revive cada día la permanencia de la guerra de 1879, donde la coyuntura histórica (Braudel 1968) actúa como un elemento de expresión constante en la cotidianidad pedagógica del conflicto de la región, tanto en educación primaria como secundaria, donde la guerra se convierte en un habitus nacionalista constante, en que se ritualiza el conflicto en fechas institucionalizadas para ello y se explican las diferencias culturales con los vecinos a través de la construcción de una otredad que data como antagónica desde 1879, como se observa en las siguientes expresiones:

En realidad, así como en Chile la Guerra del Pacífico fue parte incluso hasta el día de hoy de una cultura cívica y patriótica, en el Perú esto es mucho más fuerte debido a que el Estado quedó desarticulado después de la guerra y en cierta manera debió refundarse. Para el caso de Chile lo he llamado precisamente "el Chile patriótico", y es muy probable que la misma denominación sea aplicable al caso peruano. Más todavía, las derrotas en general cuando son heroicas suelen ser más definitorias de identidad que las victorias.

En el caso de Chile tres batallas de su historia -Rancagua en 1814, Iquique en 1879, La Concepción en 1882- son los acontecimientos más celebrados, parte de la imagi-

4 Son regiones del extremo norte de Chile, que fueron anexadas del Perú, así como la región de Antofagasta, antiguamente de Bolivia, fueron incorporadas a raíz de la Guerra del Pacífico a partir del Tratado de Ancón (1883) y de Bolivia (1904). 
nería nacional. Para el Perú, existe un antes y un después de la Guerra del Pacífico, y lo mismo desde luego en el caso de Bolivia. En cierta medida bastamente menor, esto es análogo para la mirada de Ecuador ante el Perú (Fermandois, Parodi, Zapata y González 2011).

Por lo tanto, en el norte de Chile se establecen ciertos factores que se manifiestan en la identidad regional y que obedecen a una visión de la historia como un referente de lo que fue y lo que es en la actualidad. Una zona de frontera que se construye a sí misma, dada su identificación con el conflicto mismo y con ciudades que se establecen a pesar de su origen peruano o boliviano, como chilenas. Donde sus colegios y escuelas no son ajenas a esta dinámica de reproducción cultural, que es una formación sistemática, constante y formal a través del currículum educativo, los medios masivos, los actos de las Fuerzas Armadas ${ }^{5}$ y de los mismos profesores de historia, que son los agentes de reproducción nacionalista, utilizando para ello el vehículo histórico del relato del conflicto bélico. Por tanto, existe una mitificación del rol del Estado (Cassirer 2004), expresado en héroes y su relato a través de los textos de estudio oficial, como del relato subjetivado desde un prisma nacionalista en los profesores de historia que puede generar reacciones de xenofobia en los estudiantes, dado que la temática es reciente y desde el 2003 es coyuntural, con una amplia cobertura mediática a situaciones de xenofobia en aulas y foros virtuales sobre la guerra de 1879 (Rivera 2012). ${ }^{6}$

También, en este proceso de reproducción, la prensa cotidiana se hace parte del proceso, editando materiales bibliográficos en torno a la guerra con el objetivo explícito de que este mensaje llegue a la población y escolares, como podemos observar en la siguiente cita:

Uno de los conflictos armados que, a juicio de los historiadores, nos forjó como una raza aguerrida, es sin duda la Guerra del Pacífico [...]. El conflicto generado por razones de índole económicas y por el pacto secreto de los aliados y la violación del segundo tratado de fronteras de 1874, fue un acto que nos marcó como chilenos. Y nosotros como Diarios Regionales del Norte no podríamos estar ausentes y desde hoy, entregaremos 24 capítulos de lo que fue la Guerra del Pacífico (La Estrella de Arica 2004).

5 Entre estos, resaltan el Mes del Mar (mayo en Chile), el Día del Mar para Bolivia (el 23 de marzo), la reciente inauguración del Día del Mar en Bolivia (13 de febrero) y las actividades que hace la Armada de Chile en desfiles escolares en las ciudades de Iquique, Arica y Antofagasta, enmarcadas en la celebración del Mes del Mar en Chile.

6 Existe en el sitio wwW.educarchile.cl referencias a la temática de la guerra de 1879 con introducción metodológica para el profesor de educación secundaria y primaria de Chile. 
Esta editorial pertenece al periódico más leído en la región norte de Chile y núcleo de difusión regional de la cadena editorial de El Mercurio, ${ }^{7}$ por lo cual una difusión masiva de estos textos, sumados a otros, como el de ediciones Histocomix, lleva a un lenguaje cotidiano y de rango etario infantil y juvenil de la población con el uso de dibujos y cómics de la temática de la Guerra del Pacífico, donde se lee:

Vientos de guerra soplan en la frontera norte. Tres pueblos hermanos, luchando cada uno por sus ideales, se aproximan inexorablemente hacia el conflicto. Los primeros soldados chilenos darán su pecho a la guerra en medio del desierto [...]. El pueblo chileno, en un primer momento, se mantendrá alejado. Pero un hecho sin igual, lleno de gloria y heroísmo, dejará indicado el rumbo a los chilenos... es el legado de los tripulantes de la vieja corbeta Esmeralda, es el legado de Prat (Histocomix 2003).

Entonces, los mensajes de nacionalismo tienen indicadores geográficos que unen al estudiante al espacio del norte chileno que fue el escenario de la guerra, con héroes que son figuras simbólicas de pertenencia, con un claro significado de heroísmo en la mentalidad nacional. Además de eso, desde el Ejército de Chile existe una determinación geográfica ritualista, en torno a situar a esta zona dentro de sus proyectos emblemáticos por su connotación histórica y su carácter geohistórico. Es por ello que en la planificación de Museos para el Bicentenario de la República (2010), esta institución centró en estas regiones la mayor parte de sus actividades que se tradujeron en restauraciones, edificaciones de museos y memoriales en sitios de la guerra de 1879, como los siguientes:

Museo Militar del Morro de Arica

Museo Militar de Tarapacá

Recuperación de la Ruta Histórica de la Campaña de Tarapacá

Memorial de los Héroes de la Batalla de Dolores

Restauración y Reparación del Mausoleo Militar del Maule (Vargas 2009).

La praxis hecha cotidianidad nos presenta un escenario de conmemoraciones que buscan mantener una continuidad histórica. Desde principios del siglo XX, cada año tenemos representaciones de la Batalla de Calama en Topater (23 de marzo), en Arica del Asalto y Toma del Morro (cada 07 de junio) y de forma particular en Iquique (cada 21 de mayo), la recordación de la gesta de Prat, pasa a conformar una verdadera fiesta popular, donde participan los escolares masivamente con bandas de guerra de corte marcial, en

7 El Mercurio es un periódico de carácter nacional que tiene una editorial definida de carácter conservador y es el centro de información de los diarios regionales del norte, como La Estrella de Iquique y sus símiles de las demás ciudades. 
las que los escolares de primaria y secundaria marchan en una ceremonia cívica única para escolares con sones militares y con una clara modalidad prusiana, dada la formación militar que tienen las Fuerzas Armadas, desde $1886 .{ }^{8}$ Por lo tanto, en el caso de la historia y las ciencias sociales en Chile, es un hecho que existe una reproducción sobre la guerra que se presenta de múltiples formas cotidianas, rituales y simbólicas en los escolares, con un marcado carácter mediatizado. ${ }^{9}$

Entonces, surgen múltiples desafíos que hacen imprescindible cambios importantes en cómo enfrentar la temática de la guerra con una mirada intercultural, donde hijos de peruanos y bolivianos - muchos son chilenos- nos invitan a revisar un cambio en los contenidos que se enseñan, sobre todo en la temática de la guerra. Por ejemplo: la memoria histórica de batallas y héroes no son las mismas en nuestras aulas trinacionales. Tal vez volcar el espacio de enseñanza-aprendizaje a otros aspectos de la guerra pueda aportarnos a la inclusión educativa de estos, y también lo sea la incorporación del uso de las nuevas tecnologías y la formación de los profesores desde una perspectiva crítica.

\section{LA DIDÁCTICA EN LA ENSEÑANZA DE LA GUERRA DEL PACÍFICO}

La didáctica de la guerra, como recurso pedagógico de la paz, no tiene mayores especificaciones a nivel de investigación en el continente latinoamericano. Sin embargo, han existido algunas referencias bibliográficas destacadas, que nacen con el fin de iniciar un proceso de cambio en las perspectivas de estudio de la historia. Tal vez pueda resultar paradójico que desde las aulas académicas y escolares haya un intento de un cierto cambio, mientras los Estados insisten en destacar los aspectos más tradicionales de los

8 Esta tradición ha llegado a los escolares; y es así como los colegios tienen bandas escolares, denominadas "bandas de guerra", que son idénticas a las militares, pero con músicos niños o adolescentes a la vez. Estas bandas son mixtas, aunque, a partir del 2010 el desfile militar del 21 de mayo, tuvo una variación y esta se expresó en la incorporación de la llamada "Tripulación Inmortal" de la hundida corbeta Esmeralda, es decir, desfilaron escolares y docentes del Instituto Carlos Condell de Iquique con uniformes de los tripulantes del antiguo buque entregados por la Armada de Chile. Esta actividad que involucró a escolares se repitió el 2011 y abre el desfile militar, por lo cual el día del desfile militar se inaugura con escolares vestidos de marineros de la guerra de 1879, generando un nuevo rito de exaltación de la patria chilena, como una reproducción del fenómeno nacionalista, que sumado a los desfiles de niños de preescolar, manifiesta la clara identidad de veneración secular a la guerra de 1879 y sus héroes en el sistema escolar de la zona norte de Chile.

9 A modo de ejemplo, muchos de los estudiantes universitarios de primer año aún creen que la historia estudia el pasado con fechas de batallas, líneas de tiempo horizontales y biografías de "grandes hombres". Esa concepción teórica de la historia es del siglo XIX, propia del positivismo histórico de Leopold von Ranke (1880) y fue superado por la escuela francesa de Marc Bloch y Lucien Febvre en 1929. 
conflictos. Los aportes existentes son pocos, como por ejemplo los trabajos de Cavieres (2006), Cortés (2004), y Rivera (2008), no obstante, no hay una cantidad apreciable de investigaciones sobre la temática y en ellas se relata más la perspectiva histórica de la guerra de 1879, que las posibilidades didácticas de la enseñanza de la Guerra del Pacífico.

La investigación de estos académicos es innovadora, pues consultan mediante metodologías cualitativas a los profesores básicos y estudiantes chilenos sobre la guerra de 1879, generando una descripción de las percepciones y de sus aprendizajes. Sin embargo, solo demuestran la función de textos específicos de historiadores tradicionales y modernos sobre el conflicto, y su relación con algunos aprendizajes de los estudiantes. Llegan a crear una crítica de los documentos, mediante las entrevistas y focus group, realizados en una región del norte chileno, como es Atacama, (antigua frontera norte de Chile, hasta la guerra de 1879). Los autores señalan, respecto a los estudiantes:

En el caso de los alumnos, existe un desconocimiento casi total de hitos verdaderos de la Guerra del Pacífico; sólo tienen la visión que ha sido transmitida por sus profesores y en ocasiones son orgullosos del accionar chileno en dicha guerra. Cuando se les pregunta directamente por causas, beneficios recibidos por Chile, no saben o no contestan. Se puede concluir que hay una gran deficiencia y una visión muy poco crítica con respecto a la guerra y lamentablemente una cierta desvalorización de lo peruano y boliviano. Esto último, puede estar influenciado por una suerte de xenofobia, en especial con la llegada de inmigrantes peruanos a Chile, dado que el país no estaba acostumbrado a recibir inmigrantes peruanos y bolivianos, cuando la inmigración de europeos o estadounidenses se ve como una contribución valiosa (Cortés 2004).

Y sobre las conclusiones de las percepciones de los estudiantes demuestran el efecto del discurso nacionalista, porque genera una visión determinada de los vencidos en el conflicto y, a la vez, se produce un efecto de demostración de la inferioridad del otro, en contraposición étnica con respecto al europeo, que se manifiesta en la estética como en la valoración del otro. Asimismo esta investigación, registra las percepciones de los profesores básicos sobre la temática que nos plantea:

Con relación a los profesores de Básica, no se les plantearon preguntas directas, por lo engorroso que podría ser que no conocieran algunos temas. Los profesores de enseñanza básica entregan una información distorsionada, patriotera y sin el más mínimo atisbo de crítica; allí me parece esta uno de los puntos centrales de la distorsión producida en el sistema educacional chileno. En conclusión es lamentable, pero la formación inicial de docentes en las universidades chilenas no está a la altura de generar herra- 
mientas para un proceso de integración, y de revisión de los escritos sobre la guerra. Con relación a los profesores de enseñanza secundaria, podría decir que la situación es distinta, pero existe todavía un grupo no despreciable que al analizar la Guerra del Pacifico, antepone el concepto nacionalista y de patria, pero existe otro grupo crítico, e incluso en una entrevista hablo sobre la actitud imperialista de Chile en la guerra. Además, existe cierto consenso de que Inglaterra fue el gran ganador de la guerra (Cortés 2004).

Estos profesores demuestran un mínimo manejo en el conocimiento de la Guerra del Pacífico, desde una perspectiva crítica al discurso histórico tradicional. Realizan un proceso de reproducción nacionalista que puede tener un efecto de posibles actitudes xenófobas contra los inmigrantes peruanos y bolivianos, considerando que el objetivo implícito de la investigación era percibir si existían condiciones de integración en los discursos docentes. No obstante, este discurso de integración es mínimo, tal como señala Parodi (2010:25).

Las reformas propuestas parecen manifestarse en los textos escolares de Chile recientemente publicados, los que presentan importantes modificaciones en sus secciones de actividades didácticas, las que motivan a los alumnos a establecer análisis críticos acerca de los eventos del pasado. Sin embargo, la lógica nacionalista de los discursos impresos se mantiene inalterable.

Esta percepción de Parodi sobre los textos chilenos se suma a la información recopilada por ambos académicos, la que señala que existe un habitus nacionalista, que es reproducido y naturalizado en la educación chilena a la vez y tal como en alguna otra ocasión se ha señalado (Rivera 2008), la formación nacionalista no es propia tan solo de Chile, sino también de Bolivia y Perú. Así, la reacción de los docentes peruanos muestra el revanchismo respecto a las provincias perdidas. Según el historiador Enrique Amayo (1988), la pérdida de Tarapacá supuso para el Perú un atraso en crecimiento y desarrollo económico de 30 años.

En el caso de esta yuxtaposición chilena de carácter histórica que se ha traducido en una formación sistemática del conflicto, el historiador chileno Eduardo Cavieres (2006:17) explica que la diferenciación hacia los vecinos países se forma en el siglo XIX:

El problema, por cierto, es una herencia del siglo XIX. Por una parte, el carácter de la época, formación de los Estados nacionales, necesidades territoriales, financiamiento del aparato fiscal, insistencia en las diferenciaciones, etc. Al mismo tiempo, incapa- 
cidad o despreocupación de los gobiernos y grupos dirigentes para volcar esfuerzos y decisiones a objeto de que las nuevas posibilidades económicas se transformaran también en desarrollos sociales profundos y permanentes. Como consecuencia, los conflictos externos se convirtieron en principales bases de las identificaciones nacionales y, en el tiempo, apelando a la historia de los mismos, buenos argumentos para solucionar problemas internos.

La problemática es la diferenciación contextualizada en la guerra para formarse como Estados nacionales distintos. Las guerras, como las que tuvo Chile en 1836 y 1879, son el sustento de esta diferenciación, no obstante, a nivel de Estados nacionales, según Cavieres (2006:20), la desconfianza surge en el primer conflicto, mas es el mismo Estado el generador de esta a través de sus mecanismos de reproducción cultural, como la educación:

Evidentemente, significó la formación de un imaginario colectivo que se fue convirtiendo en un contenido bastante esencial del nacionalismo del s. XIX. Este momento, en las décadas anteriores a la Guerra del Pacífico, es muy importante porque coincidió con el surgimiento del sistema nacional de educación a partir de la Ley de Instrucción Primaria de 1860 y con la expansión de la red ferroviaria que, como es bien sabido, no sólo unió territorios, sino que además fue vehículo de transmisión cultural fundamental.

Este imaginario colectivo se ve reforzado por el culto a los héroes patrios que tienen su escena histórica en la guerra de 1879. Mientras el capitán Arturo Prat personifica el heroísmo de la oficialidad, los caídos en la batalla de La Concepción se instalan en el imaginario colectivo como los mártires anónimos y populares. Así, todos los sectores sociales se ven representados en el panteón de los héroes nacionales. Como se aprecia, la ideología nacionalista cubre la historia escolar chilena con un velo épico, que evoca géneros narrativos decimonónicos. Así, la reiterativa exaltación de epopeyas y héroes de la patria descubre en los albores del siglo XXI la vigencia de la utopía patriótica y el proyecto nacional.

La instrucción se marca en los cuerpos y en las mentes de la ciudadanía con la idea del orden, deja registros de memoria en la población que recibe este modelo educativo y didáctico de la guerra de 1879, que son acompañados por la marcialidad militar. En la perspectiva de Cavieres, la reflexión de la enseñanza de la historia de la Guerra del Pacífico debe enfocarse hacia la paz y los aspectos históricos comunes de Chile y Perú, antes de sus diferencias de Estado-nación, como de los vínculos aún existentes en este período 
histórico, donde la socialización de la guerra de 1879 es efectiva y es parte de una construcción imaginaria de las sociedades guerreras de Occidente. Las sitúa en fechas simbólicas que tienen su expresión en ritualizaciones en los colegios de Chile, transferidas por los docentes. Esta transferencia, según el sociólogo Jorge Larraín (2002:157), es parte de la identidad nacional. Él plantea:

No es casualidad que la versión militar se haya asociado a la idea de raza, y la religión, por otro, porque estos dos fenómenos socioculturales se han presentado frecuentemente en la historia para una serie de fundamentalismos. La versión militar- racial de la identidad chilena es oposicional por excelencia, en el sentido de que mucho más claramente que otras versiones requieren de otro al que hay que vencer o derrotar. La guerra implica un enemigo amenazante que hay que destruir. Una identidad nacional basada en la guerra, por lo tanto se afirma en la necesidad de tener algún enemigo por destruir.

Entonces, la guerra se ha naturalizado en los chilenos desde el siglo XIX, existe en la actualidad como un imaginario de la patria, que se ritualiza por fechas transmitidas por la escuela, el Estado y sus medios de difusión, que recrean la figura del país amenazado por sus vecinos, dado que los territorios ocupados no eran 'nuestros', mas gracias a la guerra de 1879 ahora lo son y ello debe ser recordado. El simbolismo que se basa, como fuente de soporte en el concepto de lo guerrero, en la expresión identitaria, es parte importante del ethos nacional chileno, en sí, como simbolismo activo que se gatilla y que actúa como una forma asimilable a lo biológico, es decir, ante cuerpos o ideas intrusas, se activa un sistema de anticuerpos que evitan, minimizan o eliminan la bacteria invasora que pretende contaminar la idea nacional.

Es necesario revisar la historia de la Guerra del Pacífico en los tres países y sus diferentes versiones, sobre todo la de los manuales de historia, y a la vez saber cómo se realizan las clases de historia del conflicto y qué se enseña en los países involucrados y enseñar la guerra para la paz, explicar por qué Bolivia pierde el mar y Perú su región sur completa. Es por eso que la historia debe ser contada, transmitida y enseñada de otro modo a las que se ha utilizado desde el siglo XX en los tres países. Se entiende que a pesar del esfuerzo de acercamiento aún subsisten formas excluyentes y dogmáticas de mostrar el conflicto, sin extrañar que se muestre entre buenos y malos, dependiendo el bando de la nacionalidad del participante. Actualmente hacer clases de la guerra es reproducir el lenguaje militarista ritual de batallas y héroes, sean de vencedores y vencidos como resultante de una interpretación histórica asistemática de esta ciencia y de la didáctica. 
En esta línea de análisis, se defiende que se deben revelar los obstáculos epistemológicos construidos que dificultan entender la historia, es decir, desvelar la existencia de mito-historias de la guerra de 1879. Esta guerra se construye desde los tres países a partir de las memorias colectivas, como en la asociación de leyendas, que se han convertido en realidades. Los relatos de las familias que viven en zonas fronterizas, como las regiones de Arica y Tarapacá, incluyen algunos elementos que no son históricos y son construidos desde la tradición y la oralidad. Entonces, se establece en los tres países participantes una visión homérica, con una clara misión para los Estados nacionales, que necesitan de este soporte para asentar su dominio en la zona. Se construye una mitología de la guerra, que a través de la novela histórica, el relato y otros remplaza a la historia. La ficción se hace realidad histórica y a través de la enseñanza se crea un dogma que no se cuestiona, como lo afirmara Fontana (2001:19):

Todas las comunidades humanas que duran en el tiempo construyen una historia que rememora los hechos y las victorias de sus antepasados y que desempeña la función de una genealogía colectiva. Los mitos históricos nacen justamente de las incertidumbres e inseguridades de los primeros estadios de la historia.

Por lo tanto, la mito-historia se hace sólida en las comunidades como las que viven en la región del norte de Chile, construyen una historia de la guerra que se traspasa por tradiciones o novelas y en la enseñanza a través de las propias representaciones de los docentes. La historia es un soporte para los Estados nacionales, hace que los hombres, mujeres y niños valoren el pasado y el territorio conquistado por la sangre de los soldados de 1879. Hechos honorables que se manifiestan en acciones, como desfilar en las fechas recordatorias de las batallas.

Pensamos que esta situación no debe negar la posibilidad de generar visiones alternativas del conflicto, con la meta de formar una ciudadanía activa, a partir de una enseñanza distinta de la guerra de 1879. No se debe omitir la complejidad de la Guerra del Pacífico, para ello, los escolares y docentes deben conocer la guerra que se libró entre Chile, Perú y Bolivia desde variados prismas no solo de una nacionalidad, dado que se pierde la dimensión analítica; y por lo tanto, el conflicto de 1879 no debe ser evitado, ni tampoco lo debe ser el estudiante que provoca el conflicto, es más debe ser el aliado en la táctica de abrir el espacio para la interacción. Será natural que no exista una obediencia única al proyecto de integración o que todos compartan la visión; habrá múltiples visiones de un mismo hecho y aparecerán los conflictos aún latentes, las experiencias, los mitos, estereotipos y otras pantallas o canales de una imagen que ha sido congelada por las historias e identidades nacionales desde 1879. 


\section{EL PROBLEMA EPISTEMOLÓGICO DE ENSEÑAR LA HISTORIA DE LA GUERRA DEL PACÍFICO}

En un relato histórico enseñado, existe la versión oral o escrita hacia un receptor que a la vez tiene una mínima, nula o nutrida percepción de un relato. En este ejercicio existe el problema epistemológico que se detona con la información oficial o asimilada de la guerra de 1879 que provoca fronteras que separan e incluso accionan barreras para el aprendizaje (Rivera 2012:71). La historia es un soporte para los Estados nacionales, hace que los hombres, mujeres y niños valoren el pasado y el territorio conquistado por la sangre de los soldados de 1879. Hechos honorables que se manifiestan en acciones, como desfilar en las fechas recordatorias de batallas, dado que no existe una formación sistemática y especializada en el conocimiento de la historia de la guerra de 1879, al no existir textos de estudios que hagan una síntesis histórica del conflicto sin caer en visiones nacionalistas de la guerra; por ejemplo, en el texto de estudio de segundo año de educación secundaria, vigente en los colegios chilenos, la actividad de aprendizaje recomienda la siguiente lectura:

Para Aprender Más.

Libro.

Sergio Villalobos, Chile y Perú: la historia que nos une y nos separa 1535-1883. Universitaria, Santiago, 2002. Rigurosa investigación que abarca desde la llegada de Diego de Almagro hasta el término de la Guerra del Pacífico, con el objetivo de analizar las relaciones entre Chile y Perú durante el período.

Novela.

Jorge Inostroza, Adiós al séptimo de línea. Editorial Zig-Zag, Santiago, 1963 (Méndez, Santelices, Martínez y Puga 2009:174).

La sugerencia de recomendar la lectura de novelas históricas es minimizar la historia y construir desde la escuela un lenguaje mítico que reemplaza a la historia y que produce una verdad a medias, que se transforma en una mito-historia al entregar vida a personajes ficticios. El escenario se hace complejo, ya que variadas generaciones han sido formadas en la lógica de la construcción de ciudadanías por oposición al otro, no solo en Chile, sino también en Perú y Bolivia.

En la revisión tanto de los planes y programas como de los textos escolares y documentos oficiales, destacan los contenidos y orientaciones con respecto a la guerra de 1879. Sobre los planes y programas, estos datan de 1997 y a partir del 2009 han sido 
modificados o ajustados en sus orientaciones, en una política que el Ministerio de Educación ha denominado "Ajuste curricular". Sin embargo, el sentido original de los planes y programas de estudio continúa en ejercicio, y en relación a la Guerra del Pacífico señalan:

La expansión de la economía y del territorio: expansión y modernización de la economía chilena desde la Independencia hasta la Guerra del Pacífico. Las guerras del siglo XIX entre Chile y Perú-Bolivia. Incorporación de la Araucanía. Delimitación de las fronteras de Chile en el siglo XIX (Ministerio de Educación 1999:16).

Esta orientación, que permite contextualizar la historia de Chile dentro de un proceso expansivo, considera la guerra de 1879 como un hecho que hizo a Chile más extendido hacia el norte, configurando el espacio actual. Para transmitir esto al escolar, se propone:

Identifican y sitúan espacial y temporalmente los procesos históricos ocurridos en la segunda mitad del siglo XIX, vinculados con la conformación del territorio nacional.

Nos entrega como ejemplo que:

El profesor o la profesora explica un mapa de Chile en que se representa la evolución de las fronteras, tomando como referencia: la Guerra del Pacífico y los tratados con Perú y Bolivia (frontera norte y nororiente); la ocupación de la Araucanía (frontera Bío-Bío); la disputa por la Patagonia y el tratado de límites con Argentina (frontera oriental); la soberanía en el estrecho de Magallanes (frontera austral); la incorporación de la Isla de Pascua (frontera oeste). (Ministerio de Educación 1999:49).

Por lo tanto, desde el nivel central de las decisiones pedagógicas se entiende la guerra como parte de un proceso expansivo y de aumento territorial, pero los hechos históricos señalados no son todos producto de guerras, mas existe la idea de englobar todos estos hechos en un período clasificado, destacando en ellas la guerra de 1879. Como actividad se sugiere: "Actividad 3. Explican las circunstancias que dieron origen a la Guerra del Pacífico, el desarrollo de sus principales acontecimientos y sus efectos fundamentales en el desenvolvimiento histórico de las relaciones entre Chile, Perú y Bolivia."

Otro ejemplo propone que los alumnos y alumnas:

Organizados en grupos, indagan en la biblioteca acerca de la Guerra del Pacífico: las circunstancias que le dieron origen, los acontecimientos principales y la resolución del conflicto. 
Comunican en la forma de un diario mural los resultados de su trabajo al resto del curso.

Los estudiantes analizan la situación actual de las relaciones entre Chile, Perú y Bolivia, recurriendo a información relativa a las relaciones internacionales de Chile con Perú; e información sobre las reclamaciones marítimas por parte de Bolivia (Ministerio de Educación 1999:49).

En esta actividad, como lo señalan los planes de estudio, se pide indagar en biblioteca sobre los aspectos generales y se sugieren que se publiquen en diarios murales y se enlazan los resultados del conflicto con las actuales relaciones diplomáticas con los Estados de Perú y Bolivia (es interesante notar que el caso de Bolivia y su demanda de salida marítima está definida por los planes de estudio). Sin embargo, se debe considerar que estos planes y programas actualmente vigentes y apoyados por el Ajuste Curricular (Mineduc 2011), recomiendan el uso de bibliotecas, las que en cada colegio destacan por su baja cobertura en textos, más si son de la Guerra del Pacífico.

Además, la indagación es básica y sin explicitar orientación metodológica y se explica desde el pasado el presente, respecto a los resultados de la Guerra del Pacífico, por lo que el estudiante hace el juicio que las demandas territoriales son el resultado de una guerra, ganada por Chile. Asimismo, pero solo como actividad complementaria y sin la sugerencia de aprendizaje, se destaca lo siguiente:

Ejemplo complementario. Las alumnas y alumnos realizan una composición gráfica (dibujo, collage, afiche) que exprese los sentimientos que les provoca la guerra. A partir de las imágenes elaboradas, el docente conduce al curso a reflexionar acerca del impacto de la guerra en las personas afectadas, el costo humano implicado para vencedores y vencidos, y sobre la guerra como mecanismo para resolver los conflictos, vinculando estas reflexiones con lo ocurrido en Chile, Perú y Bolivia con la Guerra del Pacífico (Mineduc 1999:46).

También, en el área de indicaciones al docente, se informa: "Se espera con esta actividad reforzar la valoración de la paz y la resolución pacífica de los conflictos." (Mineduc 1999:50). Solo al final, y como actividad complementaria, se puede educar desde la paz, aunque esta indicación solamente es aplicada si el docente la considera necesario. Sin embargo, existe una intención de acercar la reflexión sobre el impacto de las guerras en la humanidad. Un profesor podría establecer relaciones entre la guerra y la paz en la historia de Chile. Además, el modelo de competencias no es desarrollado en los planes y programas a pesar de su reedición en 2004, y se percibe una ausencia en esta modalidad 
sobre la adquisición de competencias genéricas y específicas. En el caso de los trabajos de investigación no existe desarrollo de competencias genéricas, como el trabajo en equipo, ni en las competencias específicas, el desarrollo de análisis o reflexión de textos escritos; por tanto, no hay una especificación de fines pedagógicos en las indicaciones docentes, como su ausencia en las indicaciones que el mismo Ministerio de Educación sugiere.

Es por ello que se debe potenciar una política de espacios educativos, didácticos e históricos a través de comunidades o redes virtuales. No obstante, para ello, es necesaria la discusión y la instalación del debate, más allá de la historia y los mitos creados. Como plantea Eduardo Cavieres (2006), es importante el encuentro y generación de instancias de debate, dado que afectan y revelan coyunturas de estado y tensiones a nivel de Cancillerías y diplomacia de los Estados nacionales protagonistas del conflicto bélico de 1879 . Por lo tanto, no se explicita un mayor desarrollo teórico y aun metodológico de la guerra de 1879 para los docentes y estudiantes. Se establece una carencia de teorización didáctica, revelando un vacío en la formación docente. Sobre esta problemática, es preocupante notar que al no existir mayores informaciones teóricas didácticas, los profesores y profesoras actúan por su propia iniciativa, sin considerar las cargas valóricas que el tema tiene para la población. En el ciberespacio se aborda la temática con variados prismas, algunos de bastante calidad y mesurados, otros con clara tendencia nacionalista y en algunos casos con una orientación fascista ${ }^{10}$ que reflejan una actitud cultural representativa de un relato histórico excluyente y chauvinista.

Desde esta lógica, una forma apropiada de enfrentar el problema consiste en acercar la historia de la guerra de 1879 desde un enfoque multifactorial que tome en consideración lo siguiente:

1. Enlace memorias y señale pautas de entendimiento del presente que permitan conocer el pasado. Se trata, en principio, de centrarse en las actuaciones del propio país, minimizar al otro en primera instancia, al otro en su sentido ontológico del discurso pedagógico hacia el antagonista del conflicto.

2. El objetivo es disminuir los prejuicios existentes por oposición, no definirse en cuanto a identidad nacional como contrapuestos a otros, ya sean peruanos, bolivianos o argentinos, ciudadanos de países vecinos con los que Chile ha mantenido conflictos y tensiones armadas y diplomáticas.

10 Entre los sitios con mayor solidez histórica y moderación destaca el de Mauricio Pelayo www.laguerradelpacifico.cl, sin embargo existen otros como www.soberanía.cl que son nacionalistas extremos y dividen la realidad entre patriotas y entreguistas que son el sinónimo de los integracionistas. 


\section{TESTIMONIOS Y MÉTODO HISTÓRICO: PROPUESTA DIDÁCTICA INCLUSIVA PARA LA ENSEÑANZA DE LA GUERRA DEL PACÍFICO}

La propuesta didáctica se basa en activar una perspectiva desde las fuentes de la historia que educarán en la memoria histórica del estudiante sobre la guerra de 1879, para desarrollar un rescate de la importancia del pasado en la región para su solidez, como individuo, sociedad y cultura. Es decir, la historia de la guerra del Pacífico que tiene una cautela del Estado, instituciones militares y universidades, esta vez será develada desde el aula de clases en una iniciación de la historia, como estudiante a través de talleres de trabajo histórico.

En este camino, el estudiante debe acceder a los testimonios de la Guerra del Pacífico para comprender a quienes viven en la región actualmente, y quienes vivieron, dado que la región hoy es chilena, pero en el siglo XIX era peruana. Así el estudiante podrá acumular información que nutra su identidad regional no como únicamente chilena, sino que esta identidad es una significación de variadas identidades y culturas. Por tanto, esta propuesta se basa en el descubrimiento del lenguaje didáctico de las fuentes históricas como también de nuevas didácticas de conocimientos y a través de ello, descubrir nuevos saberes no solo de los estudiantes, sino también de los profesores, y esto se hace con el uso de fuentes.

Las fuentes deben ser amplias, incluir una totalidad de testimonios históricos y considerar fuentes materiales, orales e iconográficas, dado que la amplitud de estas permitirá una proyección didáctica en base a los análisis que se desprendan del uso de las fuentes.

\section{Cuadro No 1}

Fuentes históricas de la guerra de 1879: chilenas, peruanas, bolivianas y otras extranjeras

\begin{tabular}{|c|c|c|c|c|c|}
\hline $\begin{array}{c}\text { Fuentes } \\
\text { escritas }\end{array}$ & $\begin{array}{c}\text { Fuentes } \\
\text { orales }\end{array}$ & $\begin{array}{c}\text { Fuentes } \\
\text { materiales }\end{array}$ & $\begin{array}{c}\text { Fuentes ico- } \\
\text { nográficas }\end{array}$ & $\begin{array}{c}\text { Fuentes na- } \\
\text { rrativas }\end{array}$ & $\begin{array}{c}\text { Fuentes } \\
\text { audiovisuales }\end{array}$ \\
\hline \multirow{3}{*}{$\begin{array}{c}\text { Leyendas, } \\
\text { anécdotines, } \\
\text { de guerra }\end{array}$} & $\begin{array}{c}\text { Monumen- } \\
\text { novelas, } \\
\text { poemas, } \\
\text { cuentos y } \\
\text { canciones }\end{array}$ & $\begin{array}{c}\text { calles, mu- } \\
\text { ceos, restos } \\
\text { de la guerra }\end{array}$ & $\begin{array}{c}\text { Pinturas, } \\
\text { fotografías, } \\
\text { diagramas }\end{array}$ & $\begin{array}{c}\text { Crónicas, } \\
\text { memorias, } \\
\text { cartas y } \\
\text { diarios }\end{array}$ & $\begin{array}{c}\text { Documentales } \\
\text { y reportajes } \\
\text { televisivos }\end{array}$ \\
\hline
\end{tabular}

Fuente: elaboración propia 


\section{Fuentes escritas}

El estudiante descubrirá a través de la palabra los testimonios del conflicto; por tanto, si el método de la historia que analiza los documentos es el filológico-crítico, con significados generales y específicos, el fin de la propuesta se basa en interpretar las fuentes escritas. Para ello el profesor desarrollará las siguientes actividades con los estudiantes:

a) Aplicar una crítica externa e interna al documento y señalar y descubrir su veracidad respecto a la contrastación.

b) Determinar las significaciones que tienen los documentos para comprender qué buscaba la publicación.

c) Interpretar los hechos y hacer una relación con lo sucedido.

Estos documentos serán la base de la investigación, ya que se explica a los estudiantes que la mayoría de lo que saben en Chile, Perú y Bolivia es por los datos escritos y enseñados en los textos escolares, que muchas veces no consideran toda la información, sino que la seleccionan. Este conocimiento generará una apropiación efectiva del conocimiento histórico del estudiante y lo llevará a que se valora y legitime a sí mismo como un sujeto de saber.

Desde el aspecto metodológico se deben investigar los siguientes elementos:

a) Origen de la fuente.

b) Contexto tempo-espacial: autores e impacto.

c) Análisis: estructura, pretensiones de la redacción e intencionalidad.

d) Lenguaje utilizado.

e) Revisión del contenido: utiliza fuentes, provee información o reitera, fundamenta lo expuesto, interpreta o concluye sobre los hechos.

f) Contrastación o relación con sitios históricos o museos.

g) Análisis: intencionalidad implícita, su valor como fuente histórica, conclusiones finales.

Este análisis hará que el estudiante active la historia del siglo XIX y la interprete desde el siglo XXI, para que pueda establecer relaciones críticas de los documentos y fuentes históricas escritas. 


\section{Fuentes orales}

Las fuentes orales que el estudiante revise deben partir del conocimiento que estas fueron relatadas e inventadas en base a los sucesos ocurridos en 1879; señalar que tienen una carga de afectividad patriótica o personal. Para ello el estudiante revisará lo inventado de la guerra de 1879, como la presencia de hechos del presente que se ligan a la guerra; por ejemplo, la existencia de fantasmas o aparecidos de soldados en las zonas de batalla. Estas fuentes son útiles en el sentido de que permiten descubrir la relación histórica del estudiante como sujeto de historicidad, y su conocimiento de la historia a través de informaciones no institucionales, como las conductas de entrada o información familiar de tipo oral que traiga consigo. Desde el aspecto metodológico se deben de investigar los mismos elementos del punto A.

\section{Fuentes materiales}

En la región de Arica y Parinacota y de Tarapacá, la historia de la guerra de 1879 y sus vestigios están alrededor de los colegios. A modo de ejemplo, en la bahía de Iquique se encuentra hundida la corbeta Esmeralda; cercano a la ciudad de Iquique y a los pueblos de Huara y Pisagua hay sitios de batalla que junto a Museos Navales y Militares, como el del Morro de Arica o el actual de la Esmeralda, complementan una visión material de los sucesos bélicos de 1879 .

La materialidad de la guerra de 1879 es el nexo entre el presente y el pasado, la evidencia de lo trágico de la guerra, la manifestación de la continuidad histórica y una senda efectiva para transportar al estudiante al pasado; por tanto, constituye una excelente metodología didáctica como una valoración del patrimonio y la motivación de vivir la historia en los lugares en que se produjeron los hechos. A la vez se pueden visitar los monumentos o aun investigar el Mausoleo de Veteranos de la Guerra de 1879 que contiene restos de combatientes del conflicto en que cada lápida registra las batallas en que participó el soldado fallecido.

En este caso se debe implementar la observación directa de los sitios que se seleccionarán para continuar con una investigación sobre los diferentes elementos observados; a modo de ejemplo, la importancia de la geografía en la batalla de Dolores (19 de noviembre de 1879). Esta observación in situ puede complementarse con entrevistas a geógrafos o militares que entregará una confirmación de los hechos y permitirá una interpretación de los sucesos. 
La llegada a los sitios se puede clasificar en:

a) Salida a terreno: implica una intervención del campo con un conocimiento previo del sitio.

b) Visita guiada: implica una guía especializada en el sitio.

c) Observación in situ: implica la llegada e intervención del sitio con una pauta de observación.

Desde el aspecto metodológico se deben de tomar en cuenta los siguientes elementos:

1) Tema.

2) Objetivos.

3) Identificación del sitio o monumentos: considera el valor de la fuente, contexto tempo-espacial, función que tiene el sitio.

4) Observación y registro.

5) Investigación de correlación de la observación.

6) Confirmación de la observación e investigación.

7) Interpretación y análisis de los hechos.

8) Evaluación de la experiencia: participación directa del estudiante en el proceso de investigación.

\section{Fuentes iconográficas}

La región tiene una cantidad apreciable de imágenes relativas a la guerra de 1879. Estas imágenes responden a la época en que fueron escritas y que pueden ser abordadas desde la amplitud, la variedad y hasta su existencia, es decir, para qué sirven en la historia. En un proceso didáctico, es necesario desarrollar métodos de comprensión de las imágenes y se puede considerar el método crítico iconográfico que consiste en "un examen crítico icónico de la imagen, mediante lo cual se describe su contenido y se interpreta su significado, para comprender la realidad de lo cual dicho documento es testimonio" (Oliva 1998:79). En esta zona de frontera, este método puede ser aplicado a imágenes y fotos de la guerra de 1879 como vehículo de enseñanza, sobre todo en pinturas que están disponibles en unidades militares. Desde el aspecto metodológico se deben de investigar los siguientes elementos que han sido desarrollados desde perspectivas didácticas de la historia (Oliva 1998): 
1) Fuente y autor.

2) Contexto tempo-espacial.

3) Observación descriptiva: percepción de características para descubrir su sentido.

4) Observación interpretativa: se busca desentrañar la significación de la imagen para situarlo en un contexto.

5) Correlación con fuentes históricas.

6) Conclusiones.

\section{Fuentes narrativas}

La fuente narrativa es muy importante en el sentido de la innovación, dado que permite acercarse a los actores del conflicto y además hace que el estudiante pueda generarse como sujeto de saber ante su familia y motivarse al descubrir por sí mismo fuentes a las que no toda la sociedad tiene acceso. Para ello es necesario considerar el valor inmediato de la carta, dado que la carta acerca al estudiante con el soldado común, por lo que el estudiante hará viva la historia del soldado, más aún si a ello agrega el diario de campaña de los oficiales y la prensa escrita a través de corresponsales. Esto le permitirá conocer las noticias de la guerra tal como si estuviera en el siglo XIX y así también entender que esos soldados eran seres humanos, comunes y corrientes, y héroes a la vez, como son vistos por el culto cívico. Esta visión se enriquece si en estas fuentes se consideran escritos peruanos, bolivianos y extranjeros, con lo que podrá diferenciar, relacionar y aun dramatizar sucesos a través de recreaciones históricas o filmaciones de cortometrajes. Desde el aspecto metodológico se deben de investigar los siguientes elementos:

1) Origen de la fuente.

2) Contexto tempo-espacial: autores y biografía.

3) Análisis: estructura, estilo de la redacción, posibles diferenciaciones por clases sociales o nacionalidad.

4) Lenguaje utilizado.

5) Revisión del contenido: utiliza fuentes, provee información o reitera, fundamenta lo expuesto, interpreta o concluye sobre los hechos.

6) Análisis: intencionalidad implícita, su valor como fuente histórica, conclusiones finales.

7) Exposición o recreación de la revisión. 


\section{Audiovisuales}

Las fuentes audiovisuales, como películas, series televisivas y documentales, son abundantes en los tres países. Algunas están disponibles en las redes sociales y entre ellas, hay distinciones, dado que hacia 1979, al cumplirse el centenario del conflicto, Perú y Bolivia produjeron películas y documentales de marcado carácter revanchista que al ser revisado, promueven una rivalidad hacia los chilenos. Por otro lado, en Chile se editaron documentales con recreaciones históricas de batallas perdidas por los chilenos en que se resaltaba el salvajismo de los enemigos. Sin embargo, hacia la década del 2000, estas filmaciones han incorporado a académicos y se han realizado con mayor rigor histórico. No obstante, han proliferado en estos últimos años, producto de la coyuntura de las demandas marítimas de Perú y Bolivia, algunas recreaciones simuladas de una guerra entre los tres Estados en pleno siglo XXI, generando ácidos debates en las redes sociales, que son leídas por los estudiantes. Es por ello que ante esta escena de fuentes, conviene que el docente sea disciplinado en implementar elementos de análisis histórico en las producciones. Desde el aspecto metodológico se deben de investigar los siguientes elementos:

1) Origen.

2) Intencionalidad.

3) Impacto de la producción.

4) Analizar los comentarios disponibles.

5) Contrastar con fuentes históricas.

6) Entrevistar especialistas históricos.

7) Analizar la producción en base a su utilidad.

El desarrollo de estas fuentes conducirá a una mejor y efectiva comprensión de la historia de la guerra de 1879, dado que el estudiante resignificará conceptos históricos que han sido instalados en él, ya que reflexiona en torno al relato construido o heredado. Asimismo, motivará su interés por la rigurosidad del método de investigación que dinamizarán las clases expositivas, transformando a estas en un taller de activa participación estudiantil. Igualmente, los estudiantes considerarán que la historia es dinámica en cuanto a su veracidad, registrará los inventos y relacionará la guerra a la vida cotidiana de la región, pudiendo así, comprender las razones de Estado y las diferencias inventadas desde los Estados, para diferenciar a países vecinos, y a la vez valorará la visión que tiene el otro de su historia, al desarrollar en paralelo las perspectivas del conflicto.

Por un sentido de aprendizaje, el estudiante aprenderá por descubrimiento, junto al docente adquirirá los conocimientos a la par que su guía y será autor de sus propios 
análisis. A la vez esta tarea reforzará sus aptitudes científicas como sus habilidades individuales y grupales con el desarrollo de competencias como la comprensión, relación y análisis. En un aspecto personal, social e integral, el estudiante será un sujeto histórico que desarrollará su historicidad, al contemplar la memoria histórica de su pasado colectivo y proyectarlo al futuro, y se reforzará como ciudadano perteneciente a un colectivo no nacional, sino regional y americano, en condiciones de apropiarse con metodología de los conocimientos históricos que permitan cuestionar la mito-historia nacionalista de la guerra de 1879 y erigirse como una persona con criterio y racionalidad reflexiva.

\section{CONSIDERACIONES FINALES}

Desde esta perspectiva histórica, la Guerra del Pacífico puede ser tratada en aspectos comunes y aun relevantes de los que en su forma social se desconocen. Del mismo modo, el estudiante puede comprender que hubo guerra en el siglo XIX, porque había contextos diferentes a los actuales y que además no existían los mecanismos de solución de controversias que hoy están garantizados por el derecho internacional. Este tipo de planteamiento histórico puede explicar el porqué de la guerra en 1879 y, a la vez, generar una enseñanza para la paz y para la resolución de conflictos.

La guerra, necesariamente, se debe enseñar para explicar la necesidad de paz entre los Estados. La didáctica de la Guerra del Pacífico debe obedecer a marcos que no están escritos y que se instalan en las representaciones que los profesores de historia abordan en el aula sobre los sucesos transcurridos entre 1879 y 1883, revisarlos y compararlos con los planes y programas de estudio, así como con los textos escolares del Ministerio de Educación, para comprobar la propuesta del Estado y las posibilidades de la escuela.

Lamentablemente el culto a los héroes adolece de una debilidad educativa, que es crear en niños y jóvenes la idea que existen estos pequeños dioses, que son únicos e irrepetibles, demasiado inhumanos y sin errores, se concretizan en el monumento o el nombre fulgurante y marcial, dado que son reflejo de la humanidad perfecta a través de la muerte en batalla.

Esta relación de los héroes que no cuentan y que constituyeron la retaguardia de los soldados, como lo fueron sus familias y los civiles que formaron las tropas chilenas, no son incluidos. Urge indagar el porqué del héroe patrio y resignificarlo. Desde esta perspectiva aparecerán más de ellos, dado que los regimientos y tripulaciones de los bu- 
ques de guerra no eran dirigidos o conducidos por un solo hombre, sino que es una tarea colectiva con muchos de ellos omitidos.

El escenario de migración transfronteriza constante en el norte de Chile permite la proyección de una escenificación de una identidad latinoamericana que sustituya el referente histórico de cultos nacionalistas. Por tanto, sería una zona de frontera que se construye a sí misma, porque se sitúa con el conflicto mismo desde otras aristas no xenofóbicas en ciudades y localidades, antes peruanas o bolivianas, y hoy como chilenas, con una mirada de inclusión y no de exclusión.

En la concreción de este trabajo podemos señalar que esta propuesta didáctica de planteamiento inicial orientado a la enseñanza de la Guerra del Pacífico, tomando las informaciones o pretextos que los estudiantes tienen sobre la temática. En este aspecto el método a aplicar en los estudiantes será expositivo y activo, considerando la participación de temáticas de la Guerra del Pacífico, todo con enfoques reflexivos sobre el tema y por ello será de carácter significativo, centrando la acción de inicio y desarrollo pedagógico en la enseñanza previa, a través de los aprendizajes o conceptos previos que tiene el estudiante a partir de esquemas o mapas conceptuales de diagnóstico que podrán detectar sus historias anteriores.

\section{REFERENCIAS}

1. Amayo, E. 1988. La política británica en la Guerra del Pacífico. Lima: Editorial Horizonte.

2. La Estrella de Arica. 2004. "La Guerra del Pacífico." Arica: La Estrella de Arica.

3. Bourdieu, Pierre. 2003. Cuestiones de sociología. España: Editorial Istmo.

4. Braudel Fernand. 1968. La historia y las ciencias sociales. Madrid: Alianza Editorial, El Libro del Bolsillo.

5. Cassirer, Ernest. 2004. El mito del Estado. México: Fondo de Cultura Económica.

6. Cavieres, Eduardo. 2006. Chile-Perú. La historia y la escuela. Conflictos nacionales. Percepciones sociales. Valparaíso, Chile: Ediciones Universitarias de Valparaíso, Pontificia Universidad Católica de Valparaíso. 
7. Cortés, Guillermo. 2004. La Guerra del Pacífico, enseñanza en Chile, Perú y Bolivia. Consultado el 3 de agosto del 2011. (http://www.monografias.com/trabajos55/guerra-del-pacifico/ guerra-del-pacifico.shtml)

8. Fermandois, Joaquín, Daniel Parodi, Antonio Zapata y Sergio González. 2011. Generación del diálogo Chile-Perú, Perú-Chile, Documentos 2 Aspectos históricos. Lima, Perú: Primera Edición Fundación Konrad Adenauer Stiffung e Instituto de Estudios Internacionales (IDEI).

9. Fontana, Josep. 2001. La historia de los hombres. España: Ediciones Crítica.

10. Foucault, Michel. 1996. La microfísica del poder. España: Editorial La Piqueta.

11. Galtung, Johan. 1985. Sobre la paz. España: Ediciones Fontamara.

12. Histocomix. 2003. La Guerra del Pacífico. Santiago: Editorial Florencia.

13. Larraín, Jorge. 2002. Identidad chilena. Santiago: Lom Ediciones.

14. Méndez, Verónica, Carolina Santelices, Rodrigo Martínez e Isidora Puga. 2009 "Historia, Geografía y Ciencias Sociales. Texto para el estudiante. Texto de Estudio de Segundo Año de Educación Media. Santiago: Editorial Santillana.

15. Ministerio de Educación. 1999. Planes y Programas de Estudio. Segundo Año de Educación Media. Segundo Año Medio Historia y Ciencias Sociales. Santiago: Ministerio de Educación.

16._- 2011. Ajuste Curricular. Sector Historia, Geografía y Ciencias Sociales. Ministerio de Educación. Santiago: Mineduc. Consultado el 02 de agosto del 2012. (www.mineduc.cl)

17. Oliva, María A. 1998. Historia local: una invitación desde la didáctica para la enseñanza de una historia viva. Módulo de Ciencias Sociales. Santiago: Ministerio de Educación.

18. Parodi, Daniel. 2010. Lo que dicen de nosotros: la Guerra del Pacífico en la historiografía y manuales escolares chilenos. Lima: Ediciones Universidad Peruana de Ciencias Aplicadas.

19. Pelayo, Mauricio. s/f. "La Guerra del Pacífico. Los héroes olvidados.” Disponible en: www. laguerradelpacifico.cl

20. Rivera, Patricio. 2008 “Una propuesta de integración, desde la pedagogía de la historia." Tesis para optar al grado de Magíster en Integración Subregional. Universidad Arturo Prat. Iquique. Chile. 
21._ 2012. La guerra de 1879 y la integración desde la enseñanza de la historia. Iquique: Ediciones UNAP.

22. Vargas, Pamela. 2009. "Proyectos Ejércitos Bicentenario. El compromiso con la patria cumple 200 años." Revista Alborada septiembre: 3-13. 